\title{
VITAMIN D DEFICIENCY IN PATIENTS WITH CHRONIC HEART FAILURE AND MORPHO-FUNCTIONAL CONDITION OF PERIPHERAL BLOOD ERYTHROCYTES
}

DOI: $10.36740 /$ WLek202008104

\author{
Nadiia I. Baryla' ${ }^{1}$, ggor P. Vakalyuk' ${ }^{1}$, Sergii L. Popel'2 \\ ${ }^{1}$ IVANO-FRANKIVSK NATIONAL MEDICAL UNIVERSITY, IVANO-FRANKIVSK, UKRAINE \\ ${ }^{2}$ VASYL STEFANYK PRECARPATHIAN NATIONAL UNIVERSITY, IVANO-FRANKIVSK, UKRAINE
}

\begin{abstract}
The aim: To assess the vitamin D level in blood plasma of patients with chronic heart failure and to identify the effect of its deficiency on the state of peripheral blood erythrocytes during physical exertion.

Materials and methods: A total of 25 patients with CHF grade IIA stages II and III functional class were examined. The control group consisted of 25 relatively healthy people. All patients were offered to complete a 6 minutes walking test. The level of $25(\mathrm{OH}) \mathrm{D}$ total in plasma was determined by enzyme immunoanalysis. Morphological studies of erythrocytes were performed on the light-optical (Leica CME) and electron-microscopic level («JEOL-25M-T220»).

Results: Patients with chronic heart failure experienced $22.9 \%$ decrease in their vitamin D level $(17.2 \pm 0.04 \mathrm{ng} / \mathrm{ml}$ ) compared to the control group ( $38.4 \pm 0.05 \mathrm{ng} / \mathrm{ml})$. Correlation analysis showed a direct proportional relationship between vitamin $D$ deficiency and the number of erythrocytes of a modified form $(r=0.58 ; p<0.05)$ and erythrocytes with low osmotic resistance $(r=0.87 ; p<0.05)$. During the timed physical evaluation patients who experienced chronic heart failure accompanied by vitamin $D$ deficiency developed an increase in the number of their reversibly and irreversibly deformed erythrocytes and a decrease in the cellular osmotic tability.

Conclusions: During physical exertion, patients who experienced chronic heart falure accompanied by with vitamin D deficiency experienced morpho-biochemical changes in their red blood cells. These changes indicated structural disturbances in the membranes of their erythrocytes and could potentially have negative consequences for the somatic health of these patients.
\end{abstract}

KEY WORDS: chronic heart failure, vitamin D, erythrocytes, physical exertion, morpho- biochemical changes

Wiad Lek. 2020;73(8):1610-1614

\section{INTRODUCTION}

Chronic heart failure (CHF) is one of the most common and prognostically unfavorable complications of most cardiovascular system diseases (CCS) [1]. Vitamin D deficiency or deficiency of 25-hydroxy-cholecalciferol (BD) is very likely to be an additional factor in the development of this pathology $[2,15]$. The receptors for this essential substance are located in many target cells, including smooth myocytes, endothelial cells, cardiomyocytes and blood cells [3].

Scientific data points out the important role of fat-soluble vitamins in the processes of cellular metabolism and protein synthesis [15]. BD normalizes synthetic processes in the body, induces the biosynthesis of $\mathrm{Ca}^{+2}$-dependent proteins, affects proliferation and differentiation of hemopoietic stem-cells, increases the number of circulating peripheral red blood cells (EPCs); thus, it has a positive effect on hemopoiesis in general [10].

Currently there is no sufficient data regarding the relationship between the BD deficit and the state of EPC in patients with CHF; however, the results of some studies [4] indicate the important role of EPC in the transport of $\mathrm{BD}$ to various body tissues.
According to the number of researchers, the influence of $\mathrm{BD}$ on CCS includes its effect on the contractile function of the myocardium, blood pressure regulation, remodeling of the heart and reduction of left ventricular hypertrophy [8].

According to V. Povoroznyuket al., [3], a significant percentage of people with CHF experience not only the deficit of $\mathrm{BD}$, but also the disturbance of the EPC. The incidence of CHF in patients with $\mathrm{BD}$ deficiency is twice the incidence of $\mathrm{CHF}$ in patients with a sufficient level of this vitamin in the blood [6]. There is a very limited scientific data on the morphological changes of the EPC that are accompanied by $\mathrm{BD}$ deficiency in patients with $\mathrm{CHF}$ [2].

\section{THE AIM}

The paper is aimed at evaluation is to evaluate the levels of vitamin $\mathrm{D}$ in blood plasma in patients with chronic heart failure and to investigate the effect of its deficiency on the condition of peripheral red blood cells.

\section{MATERIALS AND METHODS}

25 patients (10 men and 15 women), residents of Ivano-Frankivsk, ages $59.7 \pm 6.8$ years, were included in the 
Table 1. Changes of erythrocyte indices in patients of the examination and control groups before and after the 6-min walk test ( $M \pm m)$

\begin{tabular}{ccccc}
\hline \multirow{2}{*}{ Indices } & \multicolumn{2}{c}{ Study group $(\mathbf{n = 2 5 )}$} & \multicolumn{2}{c}{ Control group (n=25) } \\
\cline { 2 - 5 } & $\begin{array}{c}\text { Before physical } \\
\text { exercise }\end{array}$ & After physical exercise & $\begin{array}{c}\text { Before physical } \\
\text { exercise }\end{array}$ & $\begin{array}{c}\text { After physical } \\
\text { exercise }\end{array}$ \\
\hline Erythrocytes, $10^{12} / \mathrm{L}$ & $4.1 \pm 0.11$ & $3.9 \pm 0.16^{*} \#$ & $4.2 \pm 0.22$ & $4.9 \pm 0.23$ \\
\hline Hemoglobin, $\mathrm{g} / \mathrm{L}$ & $144.9 \pm 2.62$ & $128.4 \pm 2.54 \#$ & $146.1 \pm 4.15$ & $146.3 \pm 2.91$ \\
\hline Hematocrit, $\%$ & $44.2 \pm 2.82$ & $46.7 \pm 1.89 \#$ & $44.90 \pm 3.93$ & $46.80 \pm 2.44 \#$ \\
\hline Mean corpuscular volume, $\mathrm{fl}$ & $89.9 \pm 5.02$ & $86.8 \pm 4.52 \#$ & $88.8 \pm 2.49$ & $92.7 \pm 2.95^{*} \#$ \\
\hline CV of erythrocytes volume, $\%$ & $11.2 \pm 1.36$ & $12.7 \pm 1.19 \#$ & $7.4 \pm 1.02^{*}$ & $8.8 \pm 1.32^{*} \#$ \\
\hline
\end{tabular}

Note: $\mathrm{CV}$ - the coefficient of variation. ${ }^{*}-\mathrm{P}<0.05$ in comparison with the control group, $\#-\mathrm{P}<0.05$ in comparison with observed results before physical exercise.

research group (DG) and examined. All patients with CHF II A were diagnosed with Vasylenko-Strazhesko, II-III functional class (FC), which was preceded by the coronary heart disease (in $62.3 \%$ of patients) and / or arterial hypertension (AG) (in $37.7 \%$ of patients) The control group (COG) consisted of 25 people without major health concerns (11 men and 14 women) $58.5 \pm 6.65$ years of age. The exclusion criteria included chronic obstructive pulmonary disease, bronchial asthma, use of hormonal drugs, diabetes mellitus, and cancer.

In order to prove CHF FC according to NYHA classification, and national guidelines of Ukraine [1], physical exercise in the form of the 6-min walk test was proposed to all patients. During the conducting of the test, a patient had to walk as long distance as possible in at own pace in 6 minutes in the corridor with 1-meter marks. Factors limiting physical exercise or any other complaints were evaluated according to the modified Borg Scale. The distance covered by the patient in 6 minutes corresponding CHF FC " 0 " is > $551 \mathrm{~m}$, CHF FC I - 426-550 m, CHF FC II - 301-425 m, CHF FC III - 151-300 m, CHF FC IV $<150 \mathrm{~m}$. At the beginning moment of the study, all patients received complex pathogenetic therapy of $\mathrm{CHF}$ according to national standard guidelines of $\mathrm{MOH}$ of Ukraine for secondary prevention of the deficiency.

We conducted a survey on exogenic consumption of $\mathrm{BD}$ with food rich on BD (cod liver oil, Omega-3, polyunsaturated fatty acids, fish oil), as well with $\mathrm{BD}$ drugs.

Evaluation of total BD level in blood plasma was provided with the enzyme-linked immunosorbent assay with detecting the total volume of 25-hydroxycalciferol $(25(\mathrm{OH}) \mathrm{D}$ total $=25(\mathrm{OH}) \mathrm{D} 3+25(\mathrm{OH}) \mathrm{D} 2)$. The volume of $25(\mathrm{OH})$ $\mathrm{D}$ in blood plasma $>30 \mathrm{ng} / \mathrm{ml}$ was considered as optimal, 20-29 $\mathrm{ng} / \mathrm{ml}$ as insufficiency, less than $20 \mathrm{ng} / \mathrm{ml}$ as the deficiency, less than $10 \mathrm{ng} / \mathrm{ml}$ as severe deficiency [10]. Blood collection for detecting of $25(\mathrm{OH}) \mathrm{D}$ in blood plasma in all examined patients was conducted in the period from October till December.

Hemoglobin, hematocrit and osmotic stability of EPClevels were determined with common methods. In order to count the total amount of EPA, analysis of blood smears was conducted with the help of Leica CME microscope with further image transferring into a digital form (Sony ExwaveHad SSC-DC58AP video camera).
During 10 minutes, blood smears were fixed in formalin vapors, then processed with $\mathrm{n}$-Butanol during 2 minutes, then immersed into the $0.01 \%$ bromophenol blue solution in the ethanol-dioxane-acetic acid solution (5:4:1) for 10 minutes and after second processing in n-Butanol was dried up during 2 minutes for study under the microscope. Counting was done per 500 cells. Photomicrography was conducted with the help of Olympus Camedia C-480 ZOOM digital camera (Olympus Corp., Japan). The images were analyzed using NIH image (Macintosh) and ScionImage (PC) software packages.

Morphologic tests of EPCmicrorelief were performed in the JEOL-25M-T220A scanning electron microscope (Japan) according to the common method [14]. It was measured the maximal minimal diameter of erythrocytes, their circumference, it was conducted percentage ratio their morphotypes before and after the 6-min walk test.

The statistical processing of examination results was provided with the help of STATISTICA 10.0 (SN AXAR207F394425FA-Q) applied software packages. The data were submitted as an average value and standard deviation $(\mathrm{M} \pm \mathrm{SD})$; by the distinctive distribution from the normal one in the form of the median (Me) and interquartile range [LQ-UQ]. To evaluate dependence between variables, it was used correlation analysis according to Spearman's criterion (R). Differences were considered significant (significant) at the level $\mathrm{p}<0.05$.

\section{RESULTS}

According to the results of the survey, it was revealed that nobody from the examination group, as well from the control group consumes $\mathrm{BD}$ rich products, and also takes $\mathrm{BD}$ containing medications on a regular basis.

The average 25(OH)D level in patients' blood plasma in the study group was $17.2 \pm 0.46 \mathrm{ng} / \mathrm{ml}$ and was 2.2 times lower $(\mathrm{p}=0.01)$ than in patients of the control group $38.4 \pm 1.22 \mathrm{ng} / \mathrm{ml}$ that was considered as BD deficiency.

According to examination results, it was determined that all patients of the study group had erythrocytes, hemoglobin and hematocrit in blood in the limits of physiological norm before the 6-min walk test, by a moderate increase of reticulocytes in comparison with the control group (table 1). 
During the morphologic examination, practically all examined patients of the study group stated an increased percentage of EPC with changed superficial relief. This correlates closely $(\mathrm{r}=0.81)$ with a decrease of their osmotic stability. At concentration of sodium chloride solutions $0.54 \%$ hemolysis occurred in $36.7 \%$ of patients of the examination group, at concentration $0.45 \%$ this occurred in $66.3 \%$ ones, at $0.40 \%$ this occurred in all patients.

Among most patients of the examination group, in peripheral blood beside normocytes, it was registered subpopulations of macrocytes and microcytes (fig. 1 a) at the background of decreased hemoglobin level (table 1).

In some patients of the examination group, reversible and irreversible changed EPCforms were present, which amount excessed the limit of the physiologic norm.

It is necessary to notice that the occurrence of these erythrocytes forms has a purely individual character for specific patients and has no statistically reliable group character $(p>0.05)$. So there were seen echinocytes with the erosion of the outer membrane (fig. $1 \mathrm{~b}$ ), and in some patients there were revealed echinocytes and acanthocytes-stomatocytes (fig. $1 \mathrm{c}, \mathrm{d}$ ).

After performing the 6-min walk test, in all patients of the examination group, it was observed a decreased amount ofEPA. Herewith it is revealed statistically reliable decreased hemoglobin level and increased hematocrit level. Electron microscopy of EPC in patients of the study group with decreased erythrocytes amounts indicates their lysis (fig. 1 e). In our study, practically all patients of the study group presented osmotic stability of erythrocytes which prominence depends on the form of the cells. The increased amount of low-density cells has an average correlation with volume of spherical EPC $(\mathrm{r}=0.58)$ and closely correlates with the $\mathrm{BD}$ deficiency level $(\mathrm{r}=0.87)$.

\section{DISCUSSION}

In recent scientific works, it was revealed that $\mathrm{BD}$ deficiency can be a factor influencing run of such diseases, like $\mathrm{AH}$, $\mathrm{CHF}$, dilated aorta and various angiopathies that are a cause of decreased adaptational potential of the body. Conducted earlier studies concerning the adaptational potential of patients with different cardiovascular diseases showed that, in $\mathrm{BD}$ deficiency, they have a lower level of functional reserves of the body [12]. Herewith a fact is known that the adaptational potential of the human and animal body depends heavily on the state of the oxygen transport system [14]. This requires closer attention of the scientists of different specialties to the morphofunctional state of EPA.

It is necessary to notice that regardless of gender difference in EPC size in the norm, patients with CHF present practically similar cells in size (in average $5.9 \pm 0.72 \mu \mathrm{m}$ ).

Herewith, revealed a clear correlation between BD deficiency in patients with different tolerance level to physical exercise during 6-min walk points that that proposed grading of morphofunctional changes of EPC can be used as a criterion for determination of physical exercise amount. This conforms to similar criteria laid down by other authors [7].
Physical exercise of different intensity level plays a large role in forming of general endurance of the body that shows up in different kinds of human activity $[11,14]$. It reflects the general level of physical efficiency of the human body. While being a multifunctional feature of the human body, the endurance integrates into itself a large amount o processes occurring on different levels: from the cellular one to the whole body $[7,11]$.

Because of the physical exercise, statistically probable increased hematocrit in 5.0\% and decreased hemoglobin level in $2.7 \%$ occur. But the physical exercise on the general background of an increased number of erythrocytes for development of hemoconcentration causes in some patients of the study group the decreased number of erythrocytes. This thing can be caused by destructive influence over erythrocytes of factors occurring during muscle activity: increased blood circulation, increased blood temperature, acidosis or alkalosis, etc. A one-time physical exercise causes an increased amount of EPC of larger size in approximately $3.0 \%(\mathrm{p}<0.05)$. Amount and volume of EPC determine rheologic blood properties. Change of these properties during the physical exercise can significantly influence oxygen transport function of the blood and is able to cause impairment in microcirculation system, thus changing functional state level of the body in patients with CHF [5]. This development mechanism of adaptational processes during the physical exercise in patients of the study group explains the more intensive aggregate capacity of erythrocytes (volume of aggregates increased in 15.6\%) and higher coefficient of their deformity (in 17.9\%) that are observed because of muscular activity and can help to increase circulating blood viscosity. Such changes in EPC indices are unfavorable for the realization of oxygen transport function of the blood and show poor adaptation of patients of the study group to the physical exercise [11].

It is known that EPC have a phenomenal property to accumulate $\mathrm{Ca}^{+2}$ salts in the setting of its decreased concentration in blood plasma unlike other cells (including also cardiomyocytes) that have its deficiency in such circumstances [5]. The increased intracellular concentration of $\mathrm{Ca}^{+2}$ plays a key role in ATP deficiency and increasing of EPC deformability itself [7].

In general significant conformation changes of EPC cause decreased erythrocyte membrane area, when it is contacting not the whole surface, but only a very small area on the tops of thorny projections. Then all depth of impaired transmembrane migration of vital substances on the level of the exchange link of hemo microcirculation in the setting of BD deficiency becomes understandable.

So most $(97.0 \%)$ patients with CHF present under the influence of physical exercise negative morphological changes in EPC that occur due to dysmetabolic disorders related to $\mathrm{BD}$ deficiency. In such consequences, the impaired structural integrity of EPC occurs that in its turn contributes to their intravascular lysis and can cause the development of anemia [7]. 

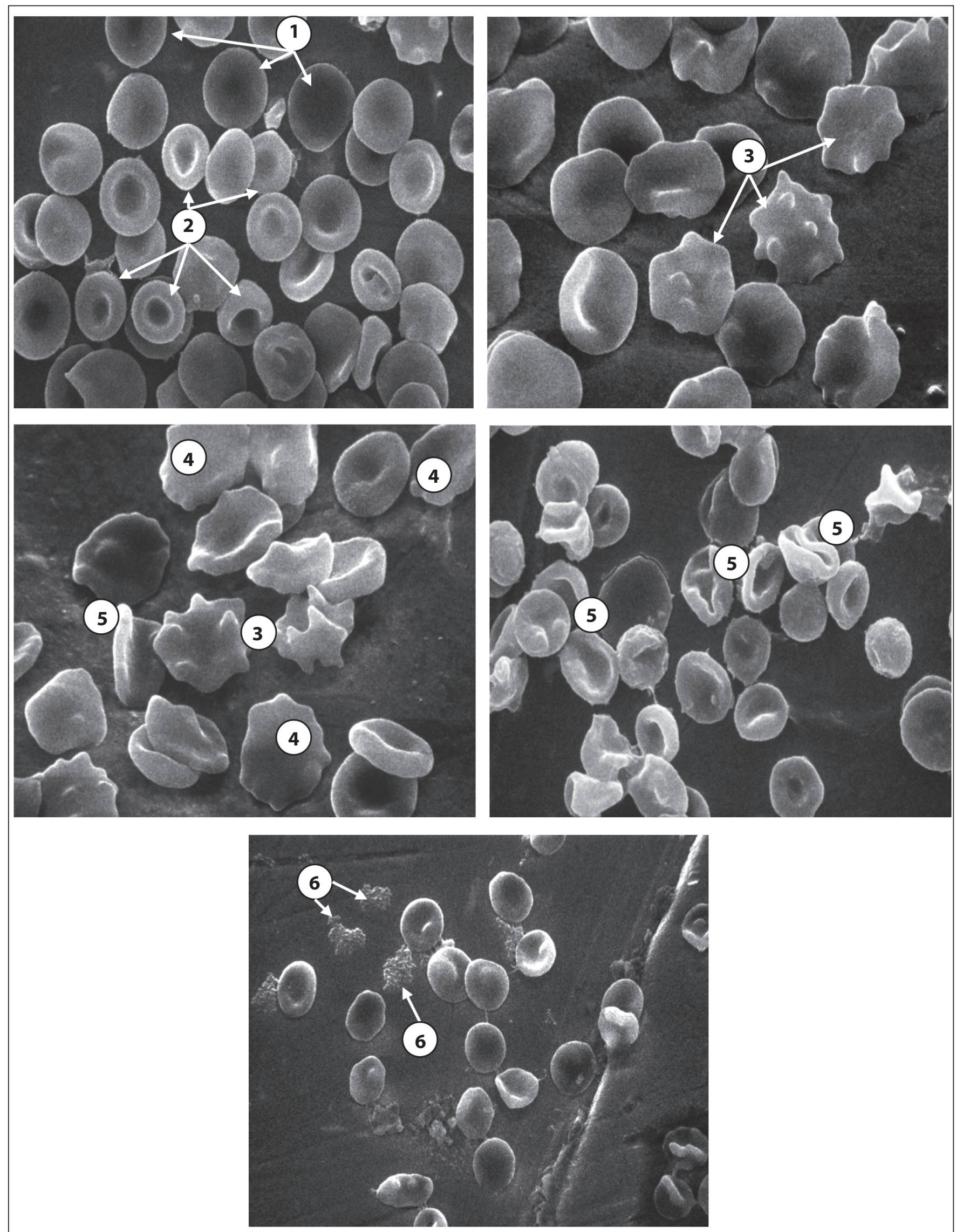

Fig. 1. Normocytes (a) and a subpopulation of macro- (1) and microcytic (2) erythrocytes, echinocytes (3), acanthocytes (4), stomatocytes (5) and lytic forms (6) in the blood of patients with chronic heart failure with vitamin deficiency D after exercise (be). Sat: a, d - 3500, b, c - 5000, e - 2000. 


\section{CONCLUSIONS}

1. An in-depth study of action mechanisms of stress level physical exercises on the state of oxygen transport system of the blood, organization of hematologic control on different therapy stages of CHF, as well during performing of corrective and restoration measures directed to remove disorders occurring as a result of $\mathrm{BD}$ deficiency, is an actual task and requires scientific justification of corresponding preventing measures for its solving.

2. During the morphological examination, practically all patients with $\mathrm{CHF}$ in the setting of BD deficiency presented heterogeneity of erythrocyte subpopulations. In peripheral blood, besides normocytes with high hemoglobinization, macro- and microcytes subpopulations were registered. Most patients presented in the setting of BD deficiency different morphologic changes of erythrocytes form presenting as echino-, acanthoand stomatocytosis that show unstable erythrocytes membranes.

3. Under the influence of dosed 6-min physical exercise, patients with CHF in the setting of BD deficiency had a decreased number of erythrocytes, but increased deformability, lysis cells were registered by a decreased amount of normocytes.

4. Revealed morpho-biochemical changes show impaired structural integrity of erythrocyte membrane components and have negative consequences regarding possible influence over the state of patients' somatic health that next to changes characteristic for CHF undergo significant stress during physical exercise in the setting of $\mathrm{BD}$ deficiency.

\section{REFERENCES}

1. Voronkov L.G. et al. Methodical recommendations of the Ukrainian Association of Cardiologists for the diagnosis, treatment and prevention of chronic heart failure in adults (short version). Eastern European Journal of Internal and Family Medicine, 2015;12(1): 65-71.

2. Morgol A.S. et al. Association of vitamin D levels in the body with the morphofunctional state of the myocardium in patients with chronic heart failure. Journal of the Grodno State Medical University. 2016;22(2): 169-176.

3. PovoroznjukV.V. et al. Role of vitamin D in pathogenesis of cardiovascular diseases. Zhurnal Grodnenskogo gosudarstvennogo medicinskogo universiteta. 2015;50(2): 6-14.

4. Shvarc G.Ja. Vitamin D deficiency and its pharmacological correction. Russian Medical Journal. 2017; 17(7): 477-486.

5. Akin F. Et al. Serum vitamin D and c-reactive protein levels are independently associated with diastolic dysfunction. J. Investig Med. 2014;62(1): 43-48.

6. Casteel B. More severe heart disease found in patients with vitamin D deficiency. Am J Med Sci. 2009 Jul; 338(1): 40-44. doi: 10.1097/ MAJ.0b013e3181aaee91
7. Chang, Y., Bo B. Effects of exhaustive exercise on the ATP-sensitive potassium channel of rat cardiac sinoatrial node. Journal of Science and Medicine in Sport. 2015;19: 65.

8. Dalbeni A. et al. Effects of six months of vitamin D supplementation in patients with heart failure: A randomized double-blind controlled trial. Nutr Metab Cardiovasc Dis. 2014;24(8): 861-868.

9. Demir M. et al. Relationship between vitamin D deficiency and non dipper hypertension. Clin. Exp. Hypertens. 2014;35(1): 45-49.

10. Holick M.F. Vitamin D (calciferol) metabolism. Reactome - a curated knowledgebase of biological pathways. 2017;63: 266-281.

11. Lambert M.I. General Adaptations-Exercise: Acute Versus Chronic and Strength Versus Endurance Training. Exercise and Human Reproduction. Springer, New York; Heidelberg Dordrecht, London. 2016. 423 p.

12. Meems L.M. et al. The vitamin D receptor activator paricalcitol prevents fibrosis and diastolic dysfunction in a murine model of pressure overload. J. Steroid Biochem Mol Biol. 2012;132: 282-289.

13. Mohammed R. Correlation between serum vitamin D level and cardiac function: Echo-cardiographic assessment. Egypt Heart J. 2015;67(4): 299-305.

14. Popel S.L. Mechanism of changing adaptation potential and morphobiochemical parameters of erythrocytes in students with different mode of day after physical load. Regulatory Mechanisms in Biosystems. 2017;8(2): 66-70.

15. Rai V. et al. Role of vitamin D in cardiovascular diseases. Endocrinology and Metabolism Clinics of North America. 2017;46(4): 1039-1059.

\section{ORCID and contributionship:}

Nadiia I. Baryla: 0000-0002-7744-2427 A,B,D

Igor P.Vakalyuk: 0000-0002-4430-6816 ${ }^{\mathrm{F}}$

Sergii L. Popel': 0000-0001-9019-3966 A,C,E

\section{Conflict of interest:}

The Authors declare no conflict of interest.

\section{CORRESPONDING AUTHOR \\ Nadiia I. Baryla}

Ivano-Frankivsk National Medical University

2 Halytska St., 76000 Ivano-Frankivsk, Ukraine

tel: +0380953876970

e-mail: nadiya27@i.ua

Received: 22.09 .2019

Accepted:03.06.2020

A - Work concept and design, B - Data collection and analysis, C - Responsibility for statistical analysis, D-Writing the article, $\mathbf{E}$-Critical review, $\mathbf{F}$ - Final approval of the article 